\title{
Pitting corrosion of galvanized pipes in hot water supply systems
}

\author{
Alexey Andrianov* \\ Moscow State University of Civil Engineering, Yaroslavskoe shosse, 26, Moscow, 129337, Russia
}

\begin{abstract}
The mechanism of pitting corrosion of galvanized pipes in hot water supply systems is considered. The analysis of the literature to determine the conditions and mechanism that cause abnormally rapid corrosion of steel galvanized water pipes in water supply systems is carried out. The results of a laboratory study of the initial stage of corrosion of galvanized pipes are presented. The results of a survey of hot water supply systems of a number of residential buildings are presented. Recommendations and measures to reduce the impact of corrosion in hot water supply systems are presented.
\end{abstract}

\section{Introduction}

\subsection{The problem of rapid corrosion of steel galvanized water pipes in hot water supply systems}

Previous studies on the corrosion of galvanized pipes have shown that important factors affecting the high corrosion rate are: incorrectness of the operating mode, uneven distribution of zinc coating thickness, the presence of welded joints and valves made of uncoated carbon steel, and low velocities of water flow, which do not ensure the removal of corrosion products from the hot water supply system [1]. However, the very mechanism of accelerated corrosion, leading to the appearance of pinholes in galvanized pipes, especially in hot water supply, remains insufficiently studied [2-5].

Figure 1 shows examples of pitting corrosion of new galvanized pipes, the service life of which does not exceed 3-4 years. These photographs were obtained by the authors in 2014-2020 during the surveys of water supply systems in various buildings. The surveys were carried out in five large residential multi-apartment buildings with one and two-zone water supply systems. Residential buildings are located in Moscow, the Moscow region and Ryazan. The main reason for the survey is the appearance of rusty water in consumers' taps and / or an abnormally high corrosion rate of hot water pipes. Below in this work, we will not consider the cases of corrosion caused by current leakage.

\footnotetext{
* Corresponding author: AndrianovAP@mgsu.ru
} 
(a)

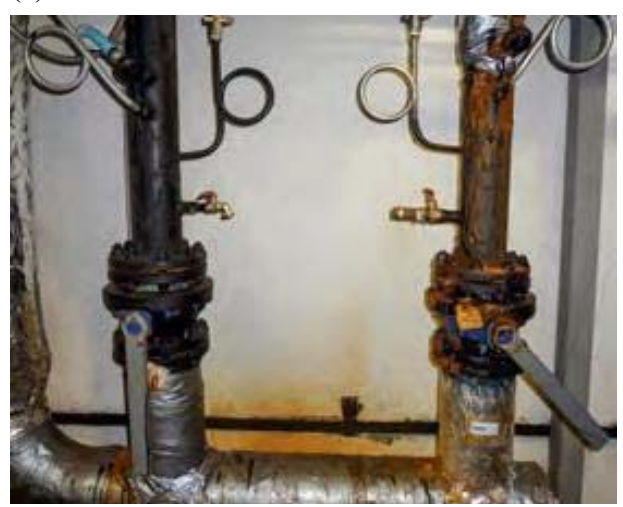

(d)

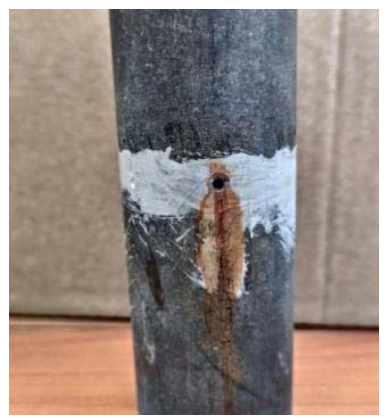

(g)

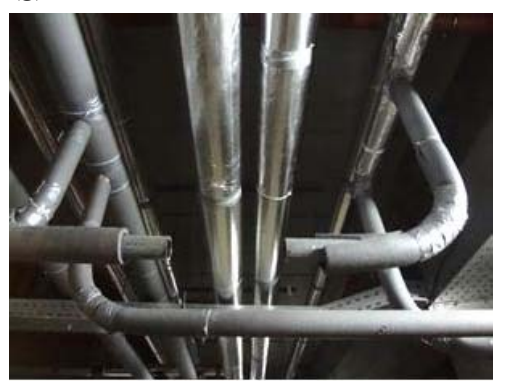

(b)

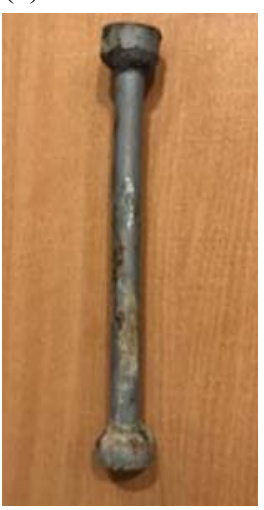

(e)

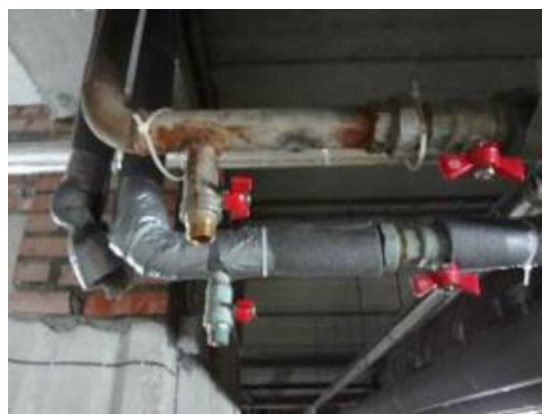

(h)

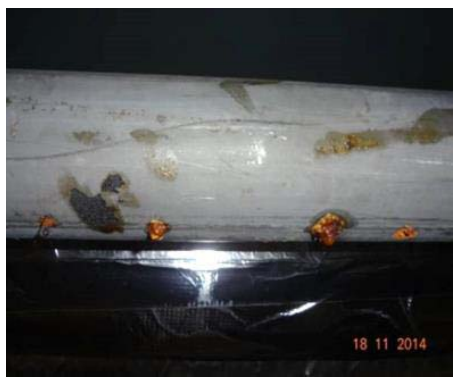

(c)

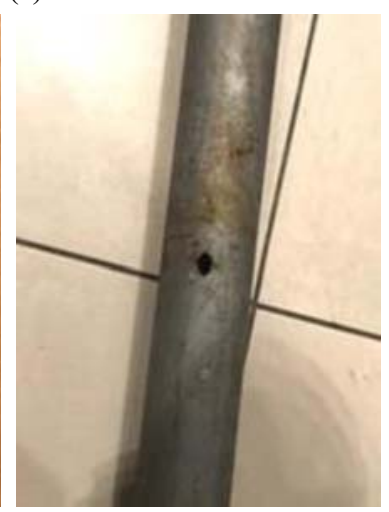

(f)

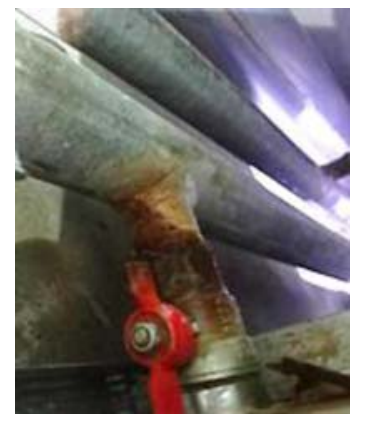

(i)

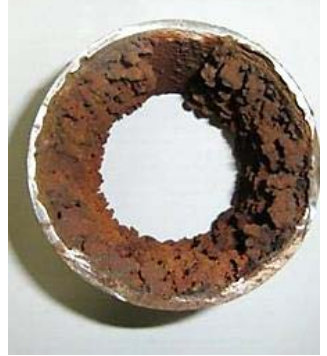

Fig. 1. Examples of pitting corrosion of galvanized pipes in hot water supply systems:

(a) pipe section in the piping of hot water supply pumps; (b), (c) a jumper at a heated towel rail on a standpipe, transition from a diameter of DN 32 to DN 15; (d) section of the standpipe DN 32;

(e) standpipe base with a drain valve; (e) section of the main pipeline with a branch to the standpipe; (g) pipes of the hot water supply system with cut out sections with through-wall pinholes; (h) pinholes along the welded seam of the horizontal main pipeline DN 100; (i) distribution of corrosion deposit along the pipe perimeter DN 100

The main places where pitting corrosion are most often observed are: long-distance main pipelines (Figures $1 \mathrm{f}$ and $1 \mathrm{~h}$ ); pipe sections adjacent to shut-off valves (Figures 1e and 1f); standpipes at the points of connection of heated towel rails (Figures $1 \mathrm{~b}$ and $1 \mathrm{c}$ ). Quite often, pitting corrosion manifests itself on the branches to the risers when the water supply pipes bypass other pipelines, which leads to the appearance of $U$ and U-shaped sections or T-shaped vertical connections to horizontal pipelines (Figure 1g). For large diameter pipes the characteristic locations of the pinholes are the weld seams located in the lower part of the horizontal pipes (Figure 1h). 
The use of welding when installing a jumper for a heated towel rail is also a common cause of pitting corrosion (Figures $1 \mathrm{~b}$ and 1c). In this case, the total number of joints on the riser is four for only one heated towel rail.

\subsection{Causes of pitting corrosion}

Pitting corrosion is understood as "localized corrosion of a metal surface, confined to a point or small area that takes the form of cavities" [6]. It is a type of corrosion with extensive corrosion at localized areas, while the rest of the surface corrodes at a much lower rate. Pitting corrosion is characteristic of metals that are passive when exposed to strong oxidants. Some metals and alloys have areas that are predominantly affected by pitting corrosion. These areas become anodes, while the rest of the metal surface is the cathode. Anode formation is a prerequisite for pitting corrosion. In this case, the formation of the anode can be caused [7]:

- heterogeneity of the metal surface. The heterogeneity of the metal surface is manifested by the presence of grain boundaries, impurities, cracks, roughness, etc. In addition, concentration cells can be formed due to differences in the effect of the environment on the metal surface;

- destruction of the passive film, which leads to the formation of many anode sections, while the rest of the surface serves as a cathode. This leads to an unfavorable area ratio;

- deposition of solid particles on the metal surface, which leads to the formation of anode and cathode areas.

A zinc coating on the inner surface prevents corrosion of the underlying steel pipe by forming a physical barrier due to corrosion-resistant deposits of zinc oxide, zinc hydroxide and zinc carbonate on the pipe surface. If there is damage to the zinc layer on the surface, then in relation to the steel base of the pipe, zinc acts as a sacrificial anode. When exposed to water, the zinc layer first corrodes (according to reaction (1)), and then a point of local penetration appears, where the zinc is depleted and the underlying steel is exposed:

$$
\begin{aligned}
& \mathrm{Zn} \rightarrow \mathrm{Zn}^{2+}+2 e^{--}, \\
& \mathrm{Fe} \rightarrow \mathrm{Fe}^{2+}+2 e^{--} .
\end{aligned}
$$

As the zinc continues to dissolve around the point of penetration and the area of the exposed steel expands, the remaining tread capacity of the zinc eventually becomes insufficient to protect the steel. Open steel begins to experience local corrosion (according to reaction (2)), forming tubercles [7].
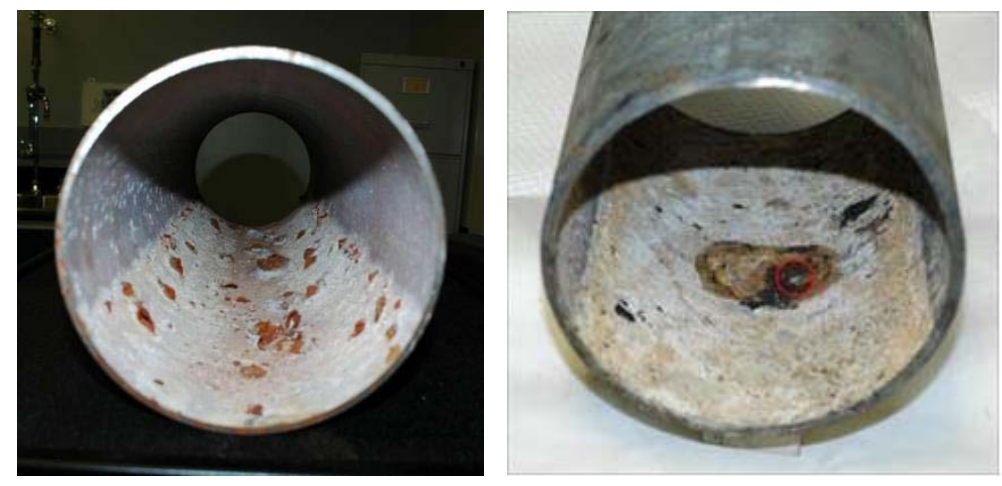

Fig. 2. Photograph showing tubercles and pinhole (circled) leakage of galvanized steel sprinkler pipe in dry pipe systems [8]. 
The role of oxygen in the appearance of pitting corrosion is especially noticeable in pipes partially filled with water. The photographs in Figure 2 obtained during the survey of fire-fighting water supply systems [8]. The illustration shows the corrosion of a galvanized steel sprinkler pipe (DN 150) in dry pipe system where residual water fills about $40 \%$ of the pipe volume.

According to the authors of [8], residual water in dry pipes is the main reason of corrosion and leakage of galvanized steel pipes in these systems. The presence of an air gap above the residual water leads to a high content of dissolved oxygen and carbon dioxide in the water and makes it corrosive towards the galvanized steel pipe.

\subsection{Corrosion of the zinc coating}

In new pipes, the corrosion of the zinc coating proceeds similarly to the corrosion of steel pipes, i.e. with oxygen depolarization. In hot water in the absence of deaeration, the oxygen content corresponds to its amount in cold water before it being supplied to the water heaters. Oxygen is released (accumulates) in low-pressure zones or along the upper part of horizontal pipes, which leads to the appearance of cathode sections of significant area on the pipe surface. The presence of a small area with a local coating defect or an inclusion more electronegative than zinc leads to the appearance of anodes on the pipe surface. Initially, the zinc coating is locally destroyed, and then the steel base of the pipe corrodes.

There are practically no studies on the corrosion of galvanized pipes. It is known that intense corrosion occurs during the first months, and then the corrosion rate decreases [9]. Tests have shown that zinc coating is destroyed most rapidly in the first months of operation. So, in the first, second and third months the thickness of the zinc coating decreased, respectively, by 17,9 and $6 \%$, while in the next 9 months - only by $1 \%$ [9].

\subsection{Pitting formation mechanism}

The further development of corrosion with a complete damage to the zinc coating can be illustrated by the scheme proposed in [10]. Figure 3 shows a diagram of pitting development in the wall of a steel pipe. The diagram shows that the presence of oxygen in the water causes corrosion. However, the formation of pitting becomes possible only when the passive film, which is located on the metal surface, is destroyed, and the potential between the cathode and the anode exceeds the value of $\mathrm{P}_{\text {pitt }}$ (pitting potential). This value can be achieved in the absence of oxygen at the point of origin of pitting. In the case of galvanized pipes, the zinc layer acts as a passive film.

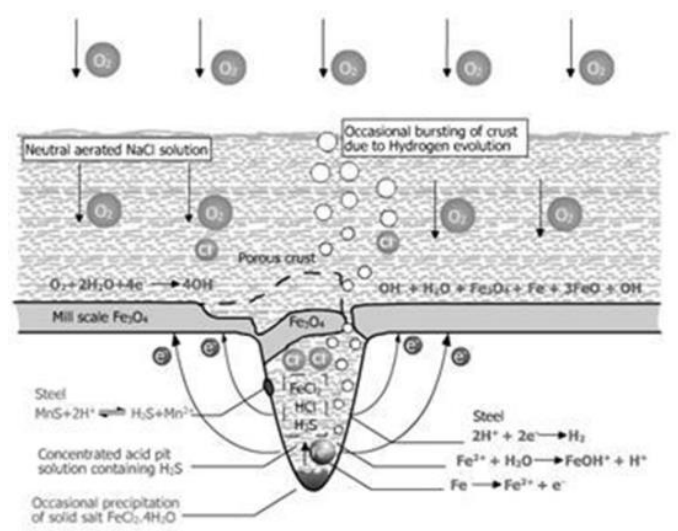

Fig. 3. Pitting formation scheme [10]. 
Pitting, as a rule, is covered by a layer of sediment $\left(\mathrm{Fe}_{3} \mathrm{O}_{4}\right.$ in the diagram) forming a tubercle. The tubercle structure is well studied and includes at least three elements: the upper surface layer, a dense layer that conducts electrons, and a loose core [11]. The source of the iron oxides that form the tubercle is the corrosive metal of the pipe and the hydroxyl ions $\mathrm{OH}^{--}$formed from the water as a result of hydrolysis. The tubercle creates a barrier between the water in the pipe and the water inside the pitting.

The accumulation of iron ions in the place of the anode (the lower part of the pitting in Figure 3) causes the diffusion of chlorides and sulfates anions from the bulk of the water. Inside the pitting, iron salts, $\mathrm{FeCl}_{2}, \mathrm{FeSO}_{4}$ are formed, which undergo hydrolysis according to reactions (3-4) [12]:

$$
\begin{aligned}
& \mathrm{FeCl}_{2}+\mathrm{H}_{2} \mathrm{O}=\mathrm{Fe}(\mathrm{OH})_{2}+\mathrm{HCl}, \\
& \mathrm{FeSO}_{4}+\mathrm{H}_{2} \mathrm{O}=\mathrm{Fe}(\mathrm{OH})_{2}+\mathrm{H}_{2} \mathrm{SO}_{4} .
\end{aligned}
$$

The characteristics of the metal and its composition, external factors such as the chemical composition and $\mathrm{pH}$ value of water, and other electrochemical factors affect the rate of formation and structure of pits. The $\mathrm{pH}$ the solution inside the pitting always differs from the bulk solution and has values below 3 as a result of hydrolysis of metal ions. The "incubation period" of pits can be months or years. The incubation period is the total time required for the structure to pass from the initiation of pitting to the moment when pitting reaches a critical degree, which ultimately leads to catastrophic destruction of the pipe metal [12].

The presence of acid accelerates the corrosion process, making it autocatalytic, i.e. practically irreversible. The acid concentration increases with the deepening of the pitting, since part of the water is consumed in the hydrolysis reaction, and the inflow of new water from the main volume of the pipe to the inside of the pitting is limited by the hole in the upper part of the tubercle and by the pressure (back-up) exerted by the generated hydrogen. Another part of the water is carried away by hydrogen bubbles, which capture and transport corrosion products in the film. The decrease in water volume explains the conical shape of the pitting. Hydrogen ions formed during hydrolysis are reduced to gaseous hydrogen (according to reaction (5)), which is removed from the corrosion zone through channels that are called chimneys in the corrosion literature [11].

$$
2 H^{+}+2 e^{-} \rightarrow H_{2} \text { (gas) }
$$

An analysis of the conditions under which the electrochemical potential exceeds the pitting potential is given in [7]. The $\mathrm{E}_{\text {pitt }}$ values were determined during potentiodynamic experiments. The paper presents the results of studies to determine the pitting potential of austenitic stainless steel [7], which can be used to explain pitting corrosion in carbon steel pipes. Pitting potential $\mathrm{E}_{\mathrm{p} i t t}$ was measured where breakage of the protective film begins and the likelihood of pitting is greatest. The potential $E_{\text {pitt }}$ often called the critical pitting or breakdown potential is a useful parameter in assessing pitting properties of materials. It should be noted that it is not an absolute parameter, and varies according to both metallurgical and electrochemical conditions [7].

The authors of the article [7] found the conditions corresponding to the transition of the metal to the passive state and associated the decrease in the density of the corrosion current in this area with the formation of iron salts, which inhibit the pitting development. Most likely, such an explanation can be accepted to the case of pitting development on a flat surface of a steel sample. But in the case of the pitting shown in Figure 3 and blocked from the main flow by tubercle structure, the decrease in the current density can be explained by the deficiency of anions (for example, chlorides), which ensure the electroneutrality of the 
solution inside the pitting. In this case, an increase in the current density is possible only due to the dissociation of water in the film adjacent to the metal surface (cathode) inside the pitting. The $\mathrm{H}^{+}$ions formed during hydrolysis then participate in the formation of gaseous hydrogen, and $\mathrm{OH}^{-}$interact with iron ions, forming a precipitate.

\section{Materials and methods}

Studies of the morphology, structure and chemical composition of the sediment formed on galvanized steel pipes were carried out on samples cut from new pipes DN 15 and DN 20 made in accordance with GOST 3262-75 (steel St37.0). The coating is hot-dip galvanized.

Moscow tap water was used as feed solution and can be characterized as slightly corrosive (Langelier index of cold water ranges from 0 to -1 ). The water quality in the period of the experiment: $\mathrm{pH}=7.8-8.0, \mathrm{t}=52-54{ }^{\circ} \mathrm{C}$, alkalinity $-3.0 \mathrm{mEq} / \mathrm{L}$, hardness $170 \mathrm{mg}-\mathrm{CaCO}_{3} / \mathrm{L}, \mathrm{Ca}^{2+}-42 \mathrm{mq} / \mathrm{l}$, TDS $-240 \mathrm{mg} / \mathrm{L}$,

The mineral composition and morphology of the sediment was assessed using SEM and EDX analysis performed with a Quanta 250 FEI with GENESIS APEX 2 EDS System with APOLLO X SDD EDAX.

\section{Results}

Figure 4a shows a photograph of the surface of a sample of a new galvanized pipe, and Figure $4 \mathrm{~b}$ shows a sample that was in an open container for 25 hours, into which a thin stream of hot water came from a water supply.

(a)

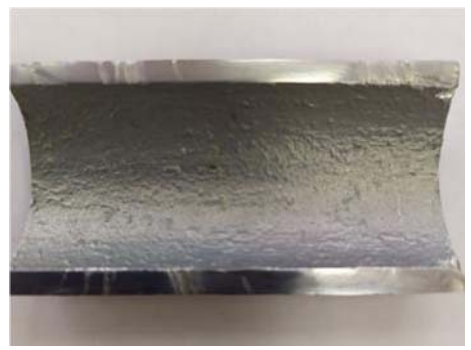

(b)

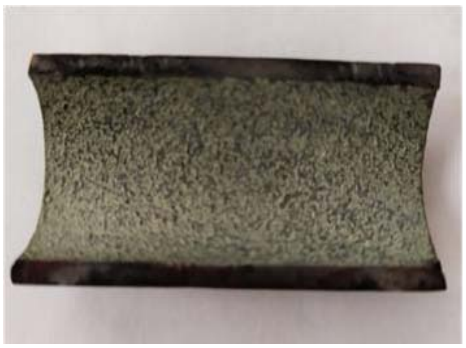

Fig. 4. The surface of galvanized pipe sample: (a) new pipe; (b) after 25 hours in hot water

(a)

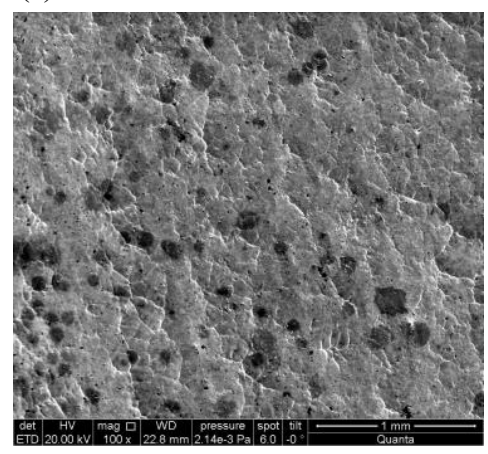

(b)

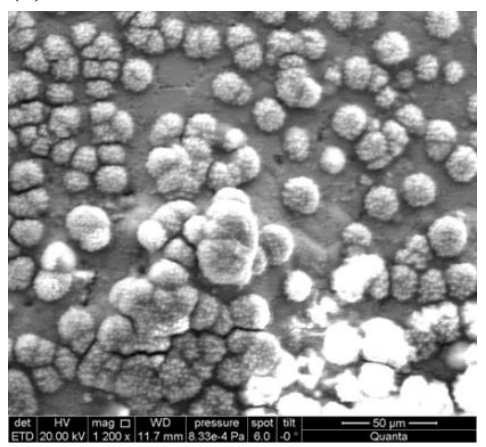

Fig. 5. SEM photos of the inner surface of a galvanized pipe sample: (a) new pipe; (b) after 25 hours in hot water 
Figure 5 shows micrographs of the surface of a new galvanized pipe (a) and the same pipe after being in hot water for 25 hours (b). From the Figure $5 \mathrm{~b}$ it can be concluded that the sediment is formed in the form of tubercles and has a crystalline, dendritic structure. In this case, corrosion occurs with oxygen depolarization.

Table 1 shows the elemental chemical composition of the pipe surface before and after immersion in water. It follows from the data that the main components of the surface layer of the new pipe are pure zinc, as well as zinc oxides and carbonates.

From a comparison of the elemental composition of the sediment on the sample surface for a new pipe and a pipe subject to short-term corrosion, it follows that there was a decrease in the zinc content in the surface layer from $82.18 \%$ for a new pipe (by weight) to $61.64 \ldots 45.27 \%$ after being in hot water, i.e. the corrosion of the zinc coating proceeds with the formation of a new protective layer consisting of zinc hydroxides and carbonates, the composition of which can be expressed by the general formula $\mathrm{mZnCO}_{3} \cdot \mathrm{nZn}(\mathrm{OH})_{2}$.

Table 1. Elemental composition of the inner surface of a galvanized pipe sample.

\begin{tabular}{|c|c|c|c|c|c|c|}
\hline \multirow{2}{*}{ Element } & \multicolumn{2}{|c|}{ New pipe } & \multicolumn{3}{c|}{ After 25 hours in hot water (two different points) } \\
\cline { 2 - 7 } & $\mathrm{Wt} \%$ & $\mathrm{At} \%$ & $\mathrm{Wt} \%$ & $\mathrm{At} \%$ & $\mathrm{Wt} \%$ & $\mathrm{At} \%$ \\
\hline $\mathrm{C}$ & 2.91 & 10.59 & 10.18 & 25.28 & 12.77 & 26.77 \\
$\mathrm{O}$ & 10.56 & 28.83 & 22.56 & 42.08 & 31.20 & 49.10 \\
$\mathrm{Al}$ & 1.56 & 2.53 & 1.83 & 2.02 & 2.49 & 2.33 \\
$\mathrm{Si}$ & 0.32 & 0.50 & 0.49 & 0.52 & 1.00 & 0.90 \\
$\mathrm{P}$ & 0.33 & 0.47 & 0.08 & 0.08 & 0.16 & 0.13 \\
$\mathrm{~S}$ & 0.33 & 0.46 & 0.30 & 0.28 & 0.50 & 0.39 \\
$\mathrm{Cl}$ & 0.33 & 0.40 & 0.22 & 0.18 & 0.38 & 0.27 \\
$\mathrm{~K}$ & 0.29 & 0.33 & 0.11 & 0.09 & 0.23 & 0.15 \\
$\mathrm{Ca}$ & 0.31 & 0.34 & 0.29 & 0.21 & 0.52 & 0.33 \\
$\mathrm{Fe}$ & 0.86 & 0.67 & 0.62 & 0.33 & 0.67 & 0.30 \\
$\mathrm{Cu}$ & - & - & 1.67 & 0.79 & 4.80 & 1.90 \\
$\mathrm{Zn}$ & 82.18 & 54.89 & 61.64 & 28.14 & 45.27 & 17.44 \\
\hline
\end{tabular}

(a)

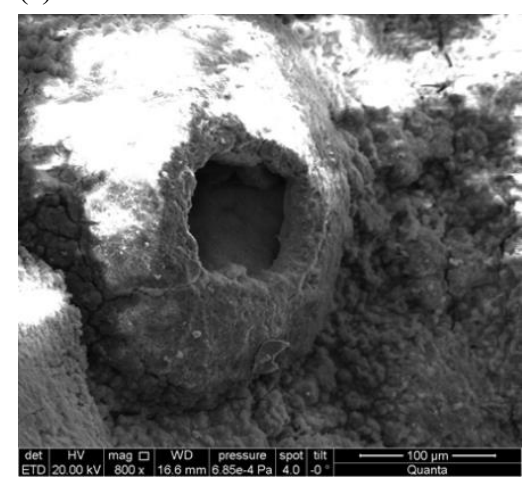

(b)

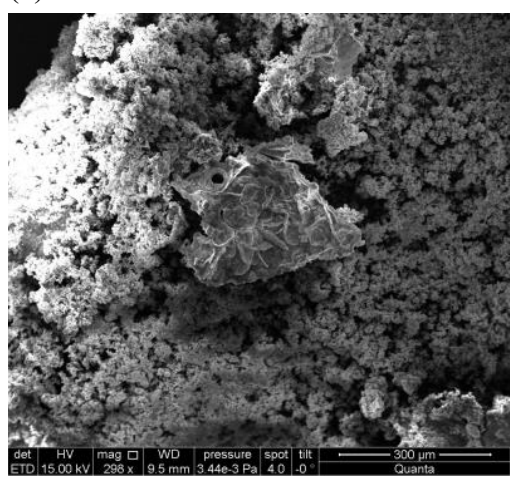

Fig. 6. SEM photos of tubercles on the surface of galvanized pipe (DN 15): (a) the base of the tubercle, (b) the reverse side of tubercle apex with a hole.

The further development of corrosion of galvanized pipes can be illustrated by the example of the following photos. Figure 6 shows micrographs of the sediment formed on the surface of a sample of a galvanized pipe DN 15 after 70 days of being in the hot water supply system with a continuous flow of hot water at a low flow rate of $30 \mathrm{l} / \mathrm{h}$, a temperature of $50 \pm 2{ }^{\circ} \mathrm{C}$ and a flow velocity of $6 \mathrm{~cm} / \mathrm{s}$. 
Figure 6a shows that the morphology of the sediment changes over time, the entire surface of the sample is covered with tubercles, and some of them have holes in the upper part. Figure $6 \mathrm{~b}$ shows the upper part of the tubercle carried away by the water flow. Apparently, after the tubercle has formed, corrosion with hydrogen depolarization continues inside the tubercle, and the tubercle collapses due to an increase in the hydrogen pressure. The source of hydrogen ions is bicarbonate ions, which determine the alkalinity of water. Table 2 shows the data on the chemical composition of the sediment forming the upper part of the tubercle, shown in Figure 6b.

Table 2. Elemental composition of the inner surface of the tubercle.

\begin{tabular}{|c|c|c|}
\hline Element & $\mathrm{Wt} \%$ & $\mathrm{At} \%$ \\
\hline $\mathrm{C}$ & 12.75 & 27.04 \\
$\mathrm{O}$ & 30.55 & 48.65 \\
$\mathrm{Fe}$ & 9.26 & 4.22 \\
$\mathrm{Cu}$ & 3.48 & 1.40 \\
$\mathrm{Zn}$ & 40.24 & 15.68 \\
\hline
\end{tabular}

It follows from Table 2 that the crystallization of zinc carbonate $\mathrm{ZnCO}_{3}$ and iron carbonate $\mathrm{FeCO}_{3}$ mainly occurs inside the tubercle. A small amount of iron in the sediment composition indicates that the zinc coating performs well protective functions within a short service life. The given examples of corrosion show that for the complete destruction of the zinc coating, longer studies are required.

\section{Discussion}

Taking into account the results of the cause studies of pitting corrosion of steel pipes (galvanized and non-galvanized), it can be concluded that the main contribution to the development of abnormally rapid corrosion in hot water supply systems is made by oxygen contained in tap water. The means of oxygen delivery to the metal surface is water flow, i.e. the creation of the oxygen concentration gradient at various points on the pipe surface, first of all, depends on the hydraulic regime of water flow.

The appearance of pinholes in the pipes shown in Figure 1 caused by a hydraulic failure. In one case, this was due to a partially open ball valve (Figure 1a), and in the other, due to the transition from a larger pipe diameter to a smaller one (Figures $1 \mathrm{~b}$ and $1 \mathrm{c}$ ). Partially closed valves or a sharp change in diameter cause the appearance of vortex flows inside the pipe, which lead to uneven aeration of the inner surface of the pipe and the appearance of pinholes. The high speed of water flow, on the one hand, promotes the passivation of the metal surface, and on the other hand, increases the rate of diffusion of metal ions from corrosion spots. Destruction occurs locally, in places where the protective film is damaged or has insufficient thickness, or there are inclusions in the zinc coating that is serve as cathodes. The turbulent regime of water flow can also lead to the destruction of tubercles, as shown in Figure 6 and form nascent pits.

Corrosion in horizontally located pipes, laid practically without a slope due to their long length (Figures 1f and 1h), can be explained by the low water velocity during periods of reduced water consumption. The low capacity of the circulation pump contributes to this process. On the inner surface of the pipe, in its upper and lower parts, there is a difference in oxygen concentrations. In this case, the upper surface (Figure 1i), in contact with oxygen in the air phase, becomes the cathode, and the lower, in contact with oxygen dissolved in water, becomes the anode. The presence of a welded seam in the lower part of the pipe accelerates the development of pitting corrosion (Figure 1h). 
Figure $1 \mathrm{~g}$ shows a photo taken in one of the surveyed houses, where the direction of water movement in some areas occurs along a U-or U-shaped trajectory in the vertical plane. With a T-shaped connection of pipes and with the movement of water from top to bottom, the air moves in a countercurrent and at a low speed of water flow, it collects along the top of the horizontal pipe, causing intense corrosion in the pipe sections which are contact with water with a lower oxygen content. In the presence of risers located far from circulation pump, hot water can enter them at a lower temperature, which in some cases leads to overturning of the circulation, i.e. to the appearance in the risers of counter flows simultaneously from the mains T3 and T4 (when hot water is supplied from above) [14]. In this case, pinholes may appear directly on the risers (Figure 1d).

There is information in the literature on the behavior of air when water moves in pipes. Air bubbles in the water begin to collapse at a fluid velocity of $0.25 \mathrm{~m} / \mathrm{s}$. When the water velocity in the pipes is more than $0.5 \mathrm{~m} / \mathrm{s}$, air bubbles move without stopping. When the velocity exceeds $1 \mathrm{~m} / \mathrm{s}$, the bubbles break into very small bubbles, forming a kind of waterair emulsion. If the velocity is lower than $0.25 \mathrm{~m} / \mathrm{s}$, then the bubbles can combine into larger ones, which leads to the airing of the pipes.

Balancing valves are installed in the hot water supply system to evenly distribute water along the risers. When the water temperature rises above the value set on the regulator, the valve closes, which leads to a reduction in water circulation through the riser, until it stops completely. When the temperature drops, the reverse process occurs - the valve opens and the water flow in the riser increases. Complete closure of the valve can adversely affect the distribution of air (and, accordingly, oxygen) in the section of the supply pipeline (from the main to the riser), since the speed of water flow becomes zero. In this case, conditions are created for the formation of local oxygen concentration gradients. It should be noted that the recommendations for the use of balancing valves in hot water supply systems have not been assessed in terms of their effect on corrosion processes.

The reasons for the accumulation of oxygen (airing) in the pipes are the following:

- absence of slopes or insufficient slopes of pipelines, which is typical for long networks;

- failure of automatic air vents on risers;

- low velocities of water flow in pipelines, which does not ensure the displacement of air plugs and the removal of corrosion products;

- unacceptable decrease in water flow with the help of shut-off valves and balancing valves;

- the opposite direction of water and air movement in pipelines;

- connection of risers to the main network according to U-, P- or T-shaped schemes in the vertical plane.

The following general recommendations can be made:

- if there are no slopes, additional automatic air vents should be installed at the highest points on the main pipelines;

- replace (and not weld) pipe sections when pinholes appear;

- increase the water consumption in the circulation mode, if necessary by replacing the circulation pump with a more powerful one;

- when rusty water appears, it is necessary to regularly flush the main pipelines with an increased flow rate in accordance with [15].

\section{Conclusions}

The analysis of the literature devoted to corrosion of steel pipes in water supply systems showed that the key factor affecting abnormally rapid corrosion and pinhole appearance is 
oxygen accumulation and uneven distribution in the pipes. This statement is confirmed by the results of a survey of hot water supply systems of a number of residential buildings.

The results of a laboratory study of the initial stage of corrosion of galvanized pipes are presented. It has been demonstrated that at the initial stage the sediment is formed already in the form of tubercles and has a crystalline, dendritic, structure. At first, corrosion occurs with oxygen depolarization, after the tubercle formation, corrosion inside it continues with hydrogen depolarization.

The survey shows that with the current trend towards an increase in the number of floors and risers in buildings and the length of main pipelines, adherence to the production and operation technology can protect the hot water supply system from abnormally rapid corrosion and ensure its trouble-free operation.

\section{References}

1. V.A. Chuhin, A.P. Andrianov, Accelerated corrosion of galvanized pipelines in the DHW system, S.O.K. 7 22-30 (2019)

2. P. Sarin, V.L. Snoeyink, D.A. Lytle, W.M. Kriven, J. Environ. Eng. 130(4) 365-373 (2004)

3. Y. Wang, G. Cheng, W. Wu, Y. Li, Corr. Sci. 130 252-260 (2018)

4. H. Sun, S. Liu, L. Sun, Int. J. Electrochem. Sci., 8 3494-3509 (2013)

5. M. Saeedikhani, S. Wijesinghe, D. J. Blackwood, Corr. Sci. 163 108-296 (2020)

6. ASM Handbook, Vol. 13A, Corrosion: Fundamentals, Testing, and Protection (ASM Inteational, 2003).

7. R.T. Loto, J. Mater. Environ. Sci. 4 (4) 448-459 (2013)

8. P. Su, D.B. Fuller, Corrosion and Corrosion Mitigation in Fire Protection Systems, 2nd Edition (FM Global, 1151 Boston-Providence Turnpike, Norwood, MA 02062, 2014)

9. B.L. Rejzin, I.V. Strizhevskij, R.P. Sazonov, Protection of hot water systems from corrosion (Strojizdat, Moscow, 1986)

10. R.T. Loto, J. Mater. Environ. Sci. 6 (10) 2750-2762 (2015)

11. T.L. Gerke, J.B. Maynard, M.R. Schock, D.L Lytle, Corr. Sci. 50 (7) 2030-2039 (2008)

12. K.V. Akpanyung, R.T. Loto, J. of Physics: Conf. Series 1378 (2019).

13. B. Mcenaney, D.C. Smith, Corr. Sci. 20 873-886 (1990)

14. N.N. CHistyakov, M.M. Grudzinskij, V.I. Livchak, I.B. Pokrovskaya, E.I. Prohorov, Improving the efficiency of hot water supply systems (Strojizdat, Moscow, 1988)

15. SP 347.1325800.2017. Internal heating systems, hot and cold water supply. Operating rules (Moscow, 2017) 